University of Nebraska - Lincoln

DigitalCommons@University of Nebraska - Lincoln

1994

\title{
Initial reference models in local earthquake tomography
}

E. Kissling

Institute of Geophysics

W. L. Ellsworth

U.S. Geological Survey

D. Eberhart-Phillips

Institute of Geological and Nuclear Sciences

U. Kradolfer

Institute of Geophysics

Follow this and additional works at: https://digitalcommons.unl.edu/usgsstaffpub

Part of the Earth Sciences Commons

Kissling, E.; Ellsworth, W. L.; Eberhart-Phillips, D.; and Kradolfer, U., "Initial reference models in local earthquake tomography" (1994). USGS Staff -- Published Research. 388.

https://digitalcommons.unl.edu/usgsstaffpub/388

This Article is brought to you for free and open access by the US Geological Survey at DigitalCommons@University of Nebraska - Lincoln. It has been accepted for inclusion in USGS Staff -- Published Research by an authorized administrator of DigitalCommons@University of Nebraska - Lincoln. 


\title{
Initial reference models in local earthquake tomography
}

\author{
E. Kissling, ${ }^{1}$ W.L. Ellsworth, ${ }^{2}$ D. Eberhart-Phillips, ${ }^{3}$ and U. Kradolfer ${ }^{1}$
}

\begin{abstract}
The inverse problem of three-dimensional (3-D) local earthquake tomography is formulated as a linear approximation to a nonlinear function. Thus the solutions obtained and the reliability estimates depend on the initial reference model. Inappropriate models may result in artifacts of significant amplitude. Here, we advocate the application of the same inversion formalism to determine hypocenters and one-dimensional (1-D) velocity model parameters, including station corrections, as the first step in the 3-D modeling process. We call the resulting velocity model the minimum 1-D model. For test purposes, a synthetic data set based on the velocity structure of the San Andreas fault zone in central California was constructed. Two sets of 3-D tomographic $P$ velocity results were calculated with identical travel time data and identical inversion parameters. One used an initial 1-D model selected from a priori knowledge of average crustal velocities, and the other used the minimum 1-D model. Where the data well resolve the structure, the 3-D image obtained with the minimum 1-D model is much closer to the true model than the one obtained with the a priori reference model. In zones of poor resolution, there are fewer artifacts in the 3-D image based on the minimum 1-D model. Although major characteristics of the 3-D velocity structure are present in both images, proper interpretation of the results obtained with the a priori 1-D model is seriously compromised by artifacts that distort the image and that go undetected by either resolution or covariance diagnostics.
\end{abstract}

\section{Introduction}

Seismic tomography applied to the solid Earth is a nonlinear process [Pavlis and Booker, 1983]. In general, solutions are obtained by linearization with respect to a reference Earth model [e.g., Aki and Lee, 1976; Nolet, 1978]. The tomographic images resulting from such linearized inversion are dependent on the initial reference models and hypocentral locations [Michael, 1988; VanderHilst and Spakman, 1989; VanderHilst et al., 1991]. This dependence, in conjunction with ambiguities intrinsic to the inversion of seismic data, is an issue that has to be addressed in any application of seismic tomography [Lees and Shalev, 1992].

Most velocity models of the Earth's interior are derived by first establishing a simple smooth model that explains some weighted average of the observations. Subsequently, this initial model is modified until a sufficient degree of coincidence between the bulk of the observations and predicted values is obtained. This procedure is followed in seismic tomographic studies, with a one-dimensional (1-D) model usually serving as the initial reference model for the threedimensional (3-D) inversion. In many previous studies the influence of the initial reference 1-D model on the results of the tomographic inversion has not been fully appreciated. In the following we show that an inappropriate initial reference model may not only affect the quality of the 3-D image by introducing artifacts, but it may also influence the confidence

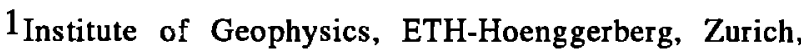
Switzerland.

2U.S. Geological Survey, Menlo Park, California.

3 Institute of Geological and Nuclear Sciences, Wellington, New Zealand.
}

Copyright 1994 by the American Geophysical Union.

Paper number 93JB03138.

0148-0227/94/93JB-03138\$05.00 calculations by underestimating the uncertainties of the results.

To overcome these problems, Kissling et al. [1984] and Kissling [1988] proposed a two-step procedure to obtain 3-D tomographic results with minimal dependence on the reference model: First, the travel time data are jointly inverted to obtain a 1-D tomographic solution, together with revised hypocenter coordinates and station corrections. We call this new model the "minimum 1-D model" [Kissling, 1988]. Second, the 3-D tomographic inversion is determined using the minimum 1-D model as the starting model. In this study we present theoretical arguments for such an approach and demonstrate its importance for 3-D tomographic results for a simple synthetic test case mimicking $S$ an Andreas Fault structure in central California.

\section{Coupled Hypocenter Velocity Model Problem}

The arrival time of a seismic wave generated by an earthquake is a nonlinear function of the station coordinates (s), the hypocentral parameters ( $h$, including origin time and geographic coordinates), and the velocity field (m).

$$
t_{\text {obs }}=f(s, h, m) \text {. }
$$

In general, neither the true hypocentral parameters nor the velocity field are known. With arrival times and station location being the only measurable quantities, we cannot solve (1) directly. To proceed, we have to make an educated guess of the unknown parameters. Using an a priori velocity model, we trace rays from a trial source location to the receivers and calculate theoretical arrival times ( $\left.t_{c a l c}\right)$. The differences between the observed and the calculated arrival time, the residual travel time ( $t_{r e s}$ ), can be expanded as functions of the differences $(\Delta)$ between the estimated and the true hypocentral and velocity parameters. To calculate suitable adjustments (corrections) to the hypocentral and model 
parameters, we need to know the dependence of the observed travel times on all parameters. For hypocenter parameters except the origin time this dependence is strongly nonlinear [e.g., Thurber, 1985], and for velocity parameters it is moderately nonlinear, even in a 1-D model [Pavlis and Booker, 1983]. Applying a first-order Taylor series expansion to (1), we obtain a linear relationship between the travel time residual and adjustments to the hypocentral $\left(\Delta \mathrm{h}_{\mathrm{k}}\right)$ and velocity $\left(\Delta \mathrm{m}_{\mathrm{i}}\right)$ parameters:

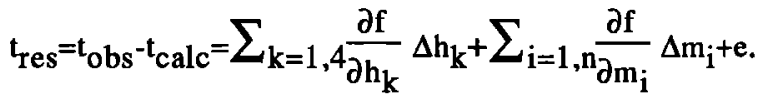

In matrix notation, the coupled hypocenter velocity model parameter relation can be written as

$$
t=H h+M m+e=A d+e
$$

t vector of travel time residuals;

$\mathrm{H}$ matrix of partial derivatives of travel time with respect to hypocentral parameters;

h vector of hypocentral parameter adjustments;

M matrix of partial derivatives of travel time with respect to model parameters;

m vector of model parameter adjustments;

e vector of travel time errors, including contributions from errors in measuring the observed travel times, errors in $t_{c a l c}$ due to errors in station coordinates, use of the wrong velocity model and hypocentral coordinates, and errors caused by the linear approximation;

A matrix of all partial derivatives;

d vector of hypocentral and model parameter adjustments.

Neglecting the effect of $(\mathrm{Mm})$ in equation (3) while locating the earthquakes, for example, has the potential to introduce systematic errors into the estimated hypocenter locations [Thurber, 1992; Eberhart-Phillips and Michael, 1993]. Similarly, neglecting of $(\mathrm{Hh})$ in equation (3) may result in biased velocity parameters [Michael, 1988; VanderHilst and Spakman, 1989]. As we demonstrate below, inclusion of both hypocenter and model parameters in the estimation procedure does not necessarily guarantee successful recovery of either true distribution.

Unless we have "guessed" the correct hypocentral coordinates, tomographic imaging with local earthquake data demands the updating of both hypocenter and velocity parameters. We concur with Thurber [1992] that this is most reliably achieved by solving the coupled hypocenter-velocity model problem, rather than alternating independent hypocenter and velocity adjustment steps. To reduce the computational burden of solving the very large system of equations (3), Pavlis and Booker [1980] and Spencer and Gubbins [1980] independently introduced an algorithm, to separate $A$ into the two smaller matrices, one containing the hypocenter location information, and one containing the model parameter information. The reduced form of A pertaining to the velocity model may then be solved separately to obtain the same solution as if the entire matrix were being inverted. Kissling [1988] demonstrated the effectiveness of the parameter separation procedure for local earthquake tomography in a test with data from Long Valley, California.
Parameter separation does not, however, reduce the dependency of the solutions on the reference velocity model or the reference hypocenters.

Generally, the solution to (3) is taken as the least squares solution that minimizes a weighted combination of the squared

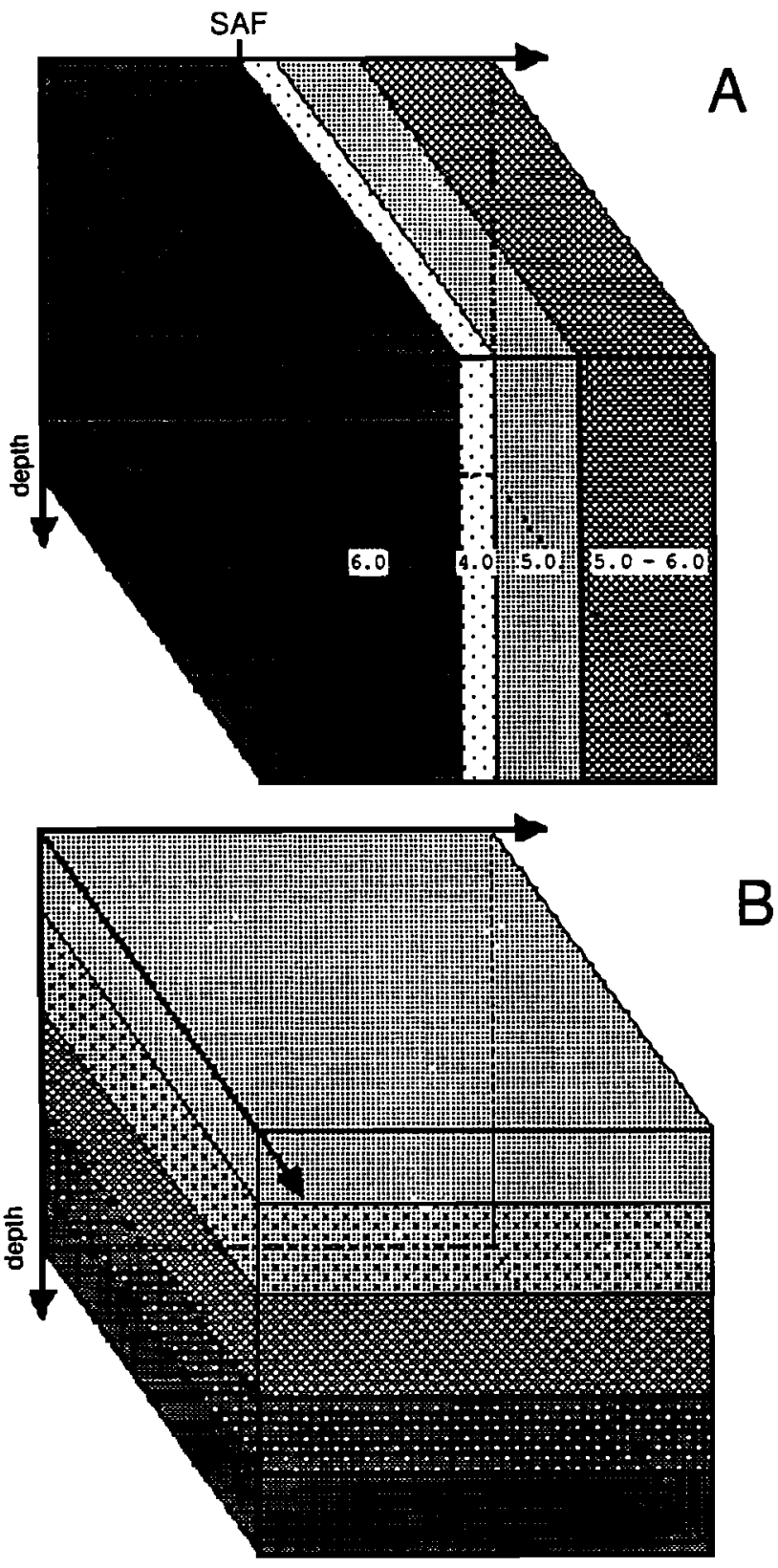

Figure 1. Schematic velocity models of the San Andreas Fault (SAF) in central California. a: Synthetic velocity model of SAF used to calculate synthetic, yet realistic data sets for the Loma Prieta earthquake series (see text). Different shading denotes different velocities (values are in kilometers per seconds). Note the lack of vertical velocity gradients and the strong lateral change in velocity. b: Schematic 1-D model used to approximate the unknown velocity structure for earthquake location and used as the reference model for 3-D tomographic inversions. The two reference $1-\mathrm{D}$ models (i.e., the refractionbased and the minimum 1-D model) have identical layer thicknesses but different layer velocities. Different shading denotes different velocities. For exact velocity values, see Figure 3. 
error ( $e^{\top} e$ ) and a measure of the velocity model change, typically its Euclidean norm $\left(\mathrm{m}^{\mathrm{T}} \mathrm{m}\right)$ [Spakman and Nolet, 1988]. Under the assumption of normally distributed errors and model perturbations, the least squares formulation results in the most likely solution that belongs to the same family of solutions as the initial reference model. By seeking a solution in the neighbourhood of the initial reference model, defects in the reference model may lead to artifacts in the 3-D tomographic images, particularly when the solution is not refined through model updating and iteration. Because the parameter space commonly contains several thousand unknowns, simple iteration schemes may be incapable of avoiding local minima and thus may not converge to the global minimum. Furthermore, the size of $A$ and/or the application of parameter separation may make it difficult, if not impossible, to compute the normal diagnostics of model performance, such as the model and data resolution matrices and model covariance matrix. Thus potential trade-off between hypocentral parameters and velocities are difficult to identify.

\section{Concept of the Minimum 1-D Model}

The chances for successful estimation of the true model using (3) can obviously be improved by selecting a starting model in the neighborhood of the true model, one for which the linearization assumption holds. The problem is how to find such a model. We suggest that the natural starting point is the 1-D velocity model that itself represents the least squares solution to (3). Not only are the algorithms for developing 1D models well studied [Crosson, 1976; Ellsworth, 1977; Roecker, 1981; Pavlis and Booker, 1983; Kissling, 1988], but also the smaller dimension of the model space makes it practical to calculate the full suite of linear diagnostics. We refer to this optimal 1-D model as the minimum 1-D model. Use of the minimum 1-D model also permits us to test for the significance of the 3-D model, since the ratio of the variance reduction for the 3-D model to the residual variance of the 3-D model, properly adjusted for degrees of freedom will follow an F distribution. This test only makes sense, however, when the reference model is itself the least squares solution for a model with fewer degrees of freedom, which will not be the case for an arbitrarily selected starting point.

In the minimum 1-D model, the layer velocities will approximately equal the average velocity in the 3-D tomographic solution within the same depth range. Note that it is not the spatial average of the model. Rather, the velocities of the 1-D model approach the average of the 3-D model elements in each layer weighted by the total ray length in each element. The initial reference model should thus be constructed using similar distribution of sources and receivers as the data set being analyzed for 3-D structure.

The determination of the minimum 1-D model is a trial and error process that ideally starts with the collection and selection of a priori information about the subsurface structure. Since this process can lead to ambiguous results, particularly when more than one a priori 1-D models have been

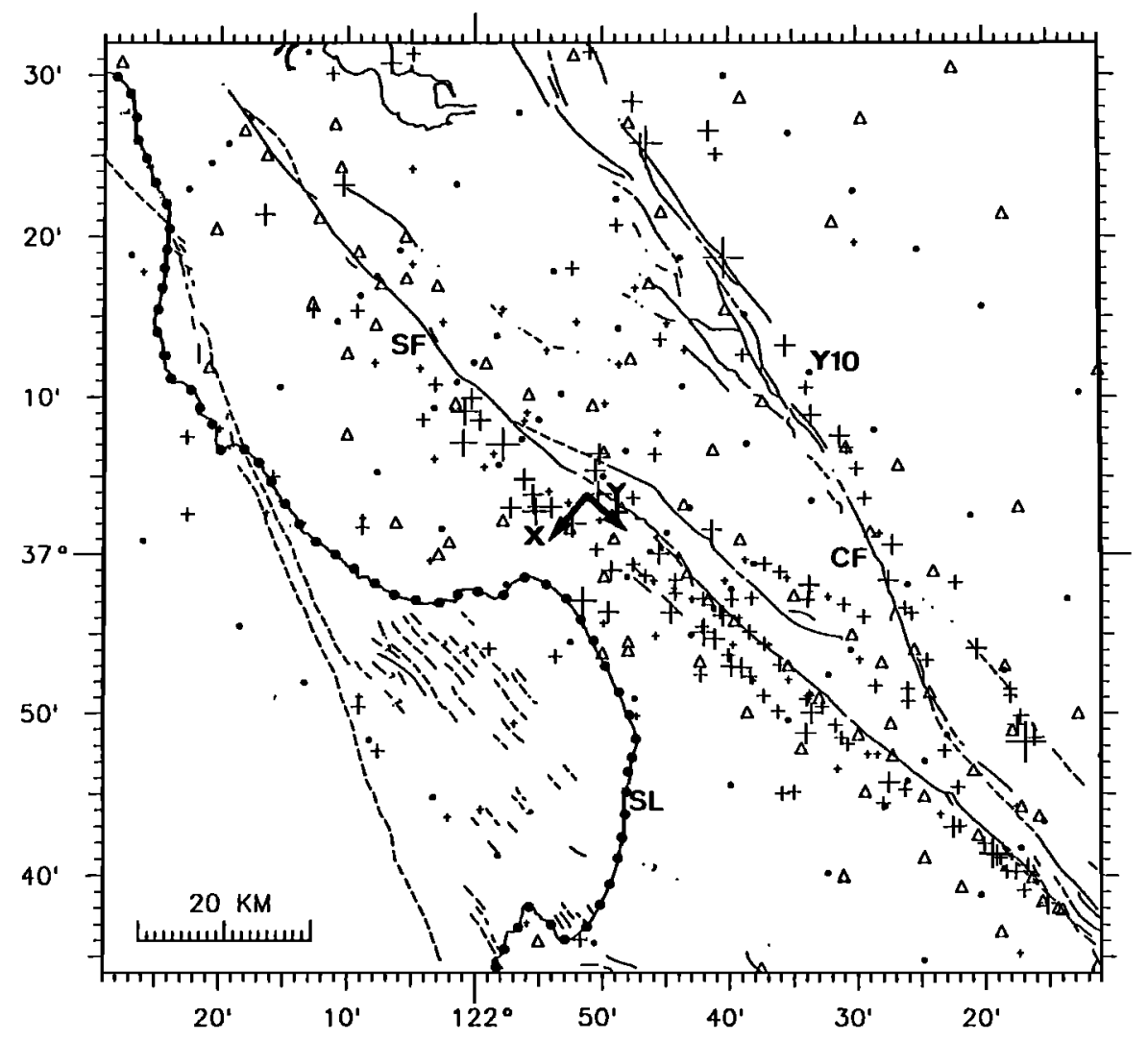

Figure 2. Seismicity in the Loma Prieta magnitude 7.1 earthquake (October 17, 1989) region. Earthquakes (crosses) that were recorded on the U.S. Geological Survey's permanent seismic station network (triangles) and that provide the basis for the synthetic data set used in the test (see text) are shown. Nodes of the velocity model grid are marked by dots. SF, San Andreas fault; CF, Calaveras fault; SL, shoreline (stippled); X,Y, Cartesian coordinate system; Y10, location of cross sections (Figure 5). 
established, several parameters that control the inversion need to be varied and the corresponding results need to be evaluated. In the appendix, guidelines for the calculation of minimum 1-D models are provided. Note that such procedures do not guarantee convergence to a best fit solution. Rather, specific characteristics of the data set and of the velocity structure need to be implemented in the calculation process. The results also depend on the effectiveness of the data selection process [Kissling, 1988].

\section{Performance of a Minimum 1-D Model as Initial Reference Model for 3-D Local Earthquake Tomography}

To test the minimum 1-D model approach, we have designed a difficult target, based upon the structure of the central creeping segment of the San Andreas fault in California. In this region, the fault juxtaposes two distinct crustal velocity structures [Walter and Mooney, 1982] and contains a tabular zone of extremely low velocity extending to seismogenic depths [Healy and Peake, 1975; Feng and McEvilly, 1983]. To amplify the effects of the horizontal gradient across the fault, our synthetic velocity model has no vertical gradient and medium-to-strong horizontal gradients (Figure 1a). Note that our minimum 1-D model with horizontal layering (Figure 1b) has an orthogonal basis to the true model. The suite of stations and earthquakes for the test (Figure 2) corresponds to the data of Eberhart-Phillips et al. [1990], which are essentially the same as those analyzed by Lees [1990] and by Foxall et al. [1993]. The reader should bear in mind, however, that the synthetic structure bears no resemblance to the structure in the Loma Prieta region, aside from the average crustal velocity outside of the anomalous zone in the synthetic model.

Using the synthetic velocity model of Figure 1a for each of the 12,000 source-receiver pairs in the Eberhart-Phillips et al. [1990] data set (199 earthquakes), we calculated travel times by solving the eikonal equations with a finite difference algorithm [Vidale, 1990]. Computational rounding errors in the travel time calculation, typically $\pm 0.01 \mathrm{~s}$, provide the only noise in the travel time data. This noise level corresponds to the standard error of " 0 weight" readings for the actual U. S. Geological Survey (USGS) data [Allen, 1982]. In the data creation phase of the experiment, W. L. Elsworth established the synthetic model, calculated the true travel times, and computed new hypocenters using a simplified 1-D model. These trial hypocenters have mislocation errors of several hundred meters to a few $\mathrm{km}$. The modelling was done by $\mathrm{E}$. Kissling and D. Eberhart-Phillips without prior knowledge of any characteristics of the synthetic velocity structure. Thus we have attempted to recreate the actual situation in which the modeler knows only the travel times and station coordinates.

With this synthetic data set, routine tomographic procedures for the inversion of local earthquake data [Kissling, 1988; Eberhart-Phillips, 1990] were performed using two similar algorithms based on work by Ellsworth [1977] and Thurber [1981], respectively. Both tomographic procedures achieve nonlinear inversion by iterating over linear inversion steps with updating of hypocenters, velocities, and ray paths. The major differences between the two methods are the approaches used for forward ray tracing (an approximate local 2D ray tracer [Thurber and Ellsworth, 1980; Kissling, 1988] versus an approximate 3-D ray tracer [Um and Thurber, 1987]), the size of the inverse problem that may be handled, and the amount of controlling and testing of the data [Kissling, 1988; Eberhart-Phillips, 1990]. While the algorithm of Kissling [1988] employs a velocity model with constant layer velocities, the algorithm of Eberhart-Phillips [1990] accounts for velocity gradients. Fortunately, the results obtained by the two inversion routines for the same parameters and assumptions were almost identical. Consequently, in the following we only show results from the inversion routine of Eberhart-Phillips [1990]. Since this method includes a 3-D search algorithm for the ray path, large systematic errors in the recognition of seismic phases due to 3-D structural effects may be excluded.

On the basis of refraction seismic studies [Mooney and Colburn, 1985] and earthquake travel time data Dietz and Ellsworth [1990] obtained a 1-D velocity model (a priori 1-D model) for the Loma Prieta area. Following the procedure outlined in the appendix, we calculated a minimum 1-D model for synthetic data with a layering identical with the a priori 1$\mathrm{D}$ model (Figure 3). We also constructed a second 1-D model that adopted the a priori velocity values but included optimal station corrections and hypocenters, just as was done with the minimum 1-D model. This initial part of the inversion process thus produced two parallel estimates, one for each 1-D model (a priori 1-D model and minimum 1-D model).

The performance of these two 1-D models is very similar, achieving rms misfits of 0.08 and $0.07 \mathrm{~s}$, respectively. The epicenters of each model are systematically repelled from the tabular low velocity zone of the true model, as would be expected, by an average of $2 \mathrm{~km}$. Focal depths are biased toward too shallow depth by $2 \mathrm{~km}$ in the a priori 1-D model but are unbiased, on average in the minimum 1-D model. This result is not unexpected, since the a priori model projects velocity model errors into depth and origin time, on average. Origin times are too early by a median value of $0.2 \mathrm{~s}$ in both models, however.

Subsequently, we performed two complete 3-D inversions of the synthetic travel time data set, one with the a priori 1-D model and one with the minimum 1-D model. Except for the 1D model aspect, the control parameters for the two 3-D inversions were identical. Synthetic quarry blast from 16 surface sources with known coordinates, but unknown origin times, were also included in the 3-D data set. The two 3-D tomographic images were calculated by inverting the travel times in an iterative process (six iterations) without using station corrections. Convergence to a stable minimum was achieved in both cases, with iteration termination controlled by an $F$ test.

The results of these parallel inversions (Figures 4 and 5) are tomographic images of the same synthetic model (Figure 1a) for the same original local earthquake data set. The differences in these 3-D results, therefore, may be fully attributed to the use of different starting layer velocities and trial hypocenters. The resulting velocity models (Figures 4 and 5) reproduce many of the long- wavelength features of the true model, particularly for the model nodes at depths of 3 and $7 \mathrm{~km}$. Each model also significantly reduces the hypocentral errors. Median epicentral errors are 0.6 and $1.0 \mathrm{~km}$ for the minimum 1-D and a priori 1-D solutions, respectively, while median depth errors are 0.2 and $-0.6 \mathrm{~km}$, and median origin time errors are -0.01 and $-0.08 \mathrm{~s}$, respectively.

The resolution matrix for the two cases are virtually identical, suggesting that there are no important differences in sampling between the two ray sets. The standard error 


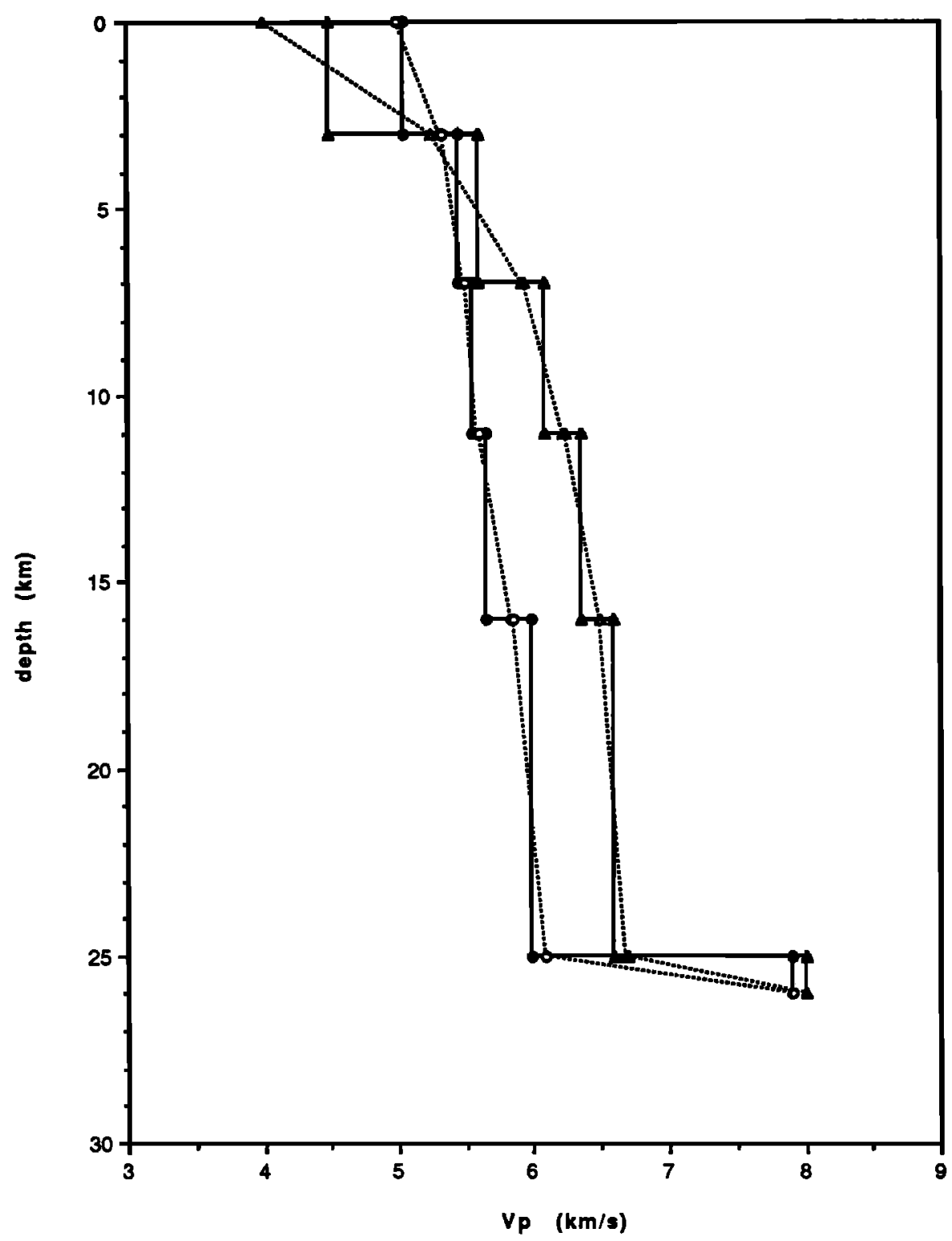

Figure 3. Velocity-depth functions for the two 1-D models of Loma Prieta, California, used for relocation of earthquakes (constant layer velocity model shown by solid lines) and as initial reference models for 3-D tomographic inversions (velocity-gradient models shown by dotted lines). Solid triangles, Dietz and Ellsworth [1990] 1-D model based on seismic refraction and earthquake data. Open circles, minimum 1-D model obtained by joint inversion of travel time data for earthquake location and layer velocities (see text).

estimates for the velocity parameters average about $0.08 \mathrm{~km} / \mathrm{s}$ for both test cases in areas of good resolution. While the standard error estimates are equivalent for either initial reference model, the standard deviation of the actual velocity errors is $0.67 \mathrm{~km} / \mathrm{s}$ for the a priori $1-\mathrm{D}$ model and $0.26 \mathrm{~km} / \mathrm{s}$ for the minimum 1-D model.

Overall, the solution obtained with the minimum 1-D model outperforms the a priori 1-D model results. A comparison of the Figures 4 and 5 reveals a strong dependence of the tomographic results on the initial reference model and reveals the potential of the minimum 1-D model to reduce artifacts in the solution that distort the 3-D velocity field in these layers for the a priori 1-D model. A quantitative assessment may be made by comparing the model and true velocity fields in regions with acceptable model resolution. Using a diagonal resolution value of 0.25 as the cut-off, the correlation coefficient between the minimum 1-D solution and true model is 0.88 , while for the a priori model it is only 0.54 . The correlation is highly significant for both models ( $p>0.001)$. The performance of the a priori model for estimating the relative horizontal velocity pattern in each layer is somewhat more satisfactory (correlation coefficient is 0.76 ), although the minimum $1-\mathrm{D}$ model is clearly superior $(0.92)$.

\section{Discussion and Conclusions}

Solutions to the local earthquake tomography are based on iterative refinement of a linearized approximation to a nonlinear function. Reliability measures for the least squares solution are also dependent on the validity of the linearization. We have shown here a clear dependence of the solution and its diagnostic measures on the initial reference 


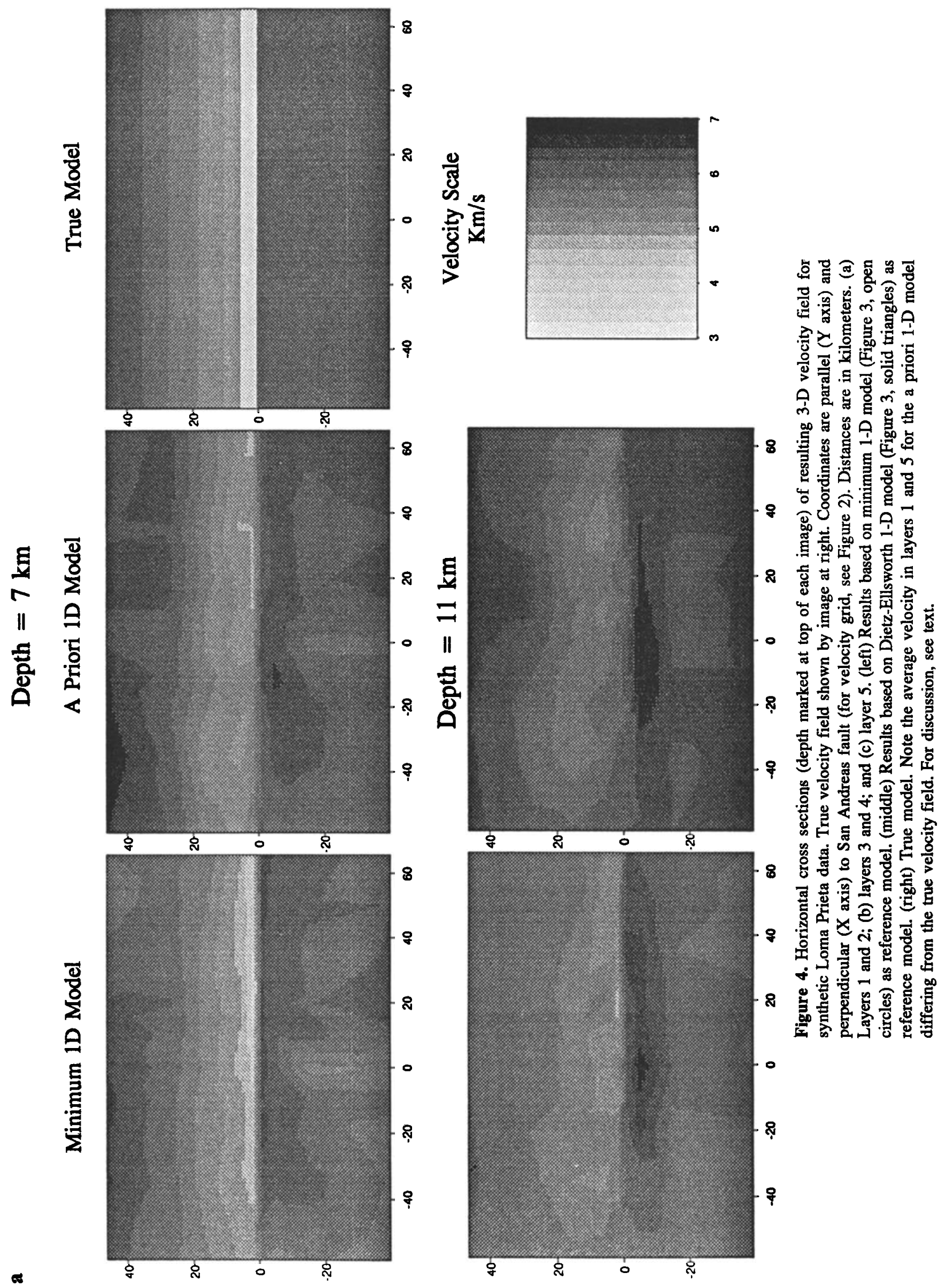




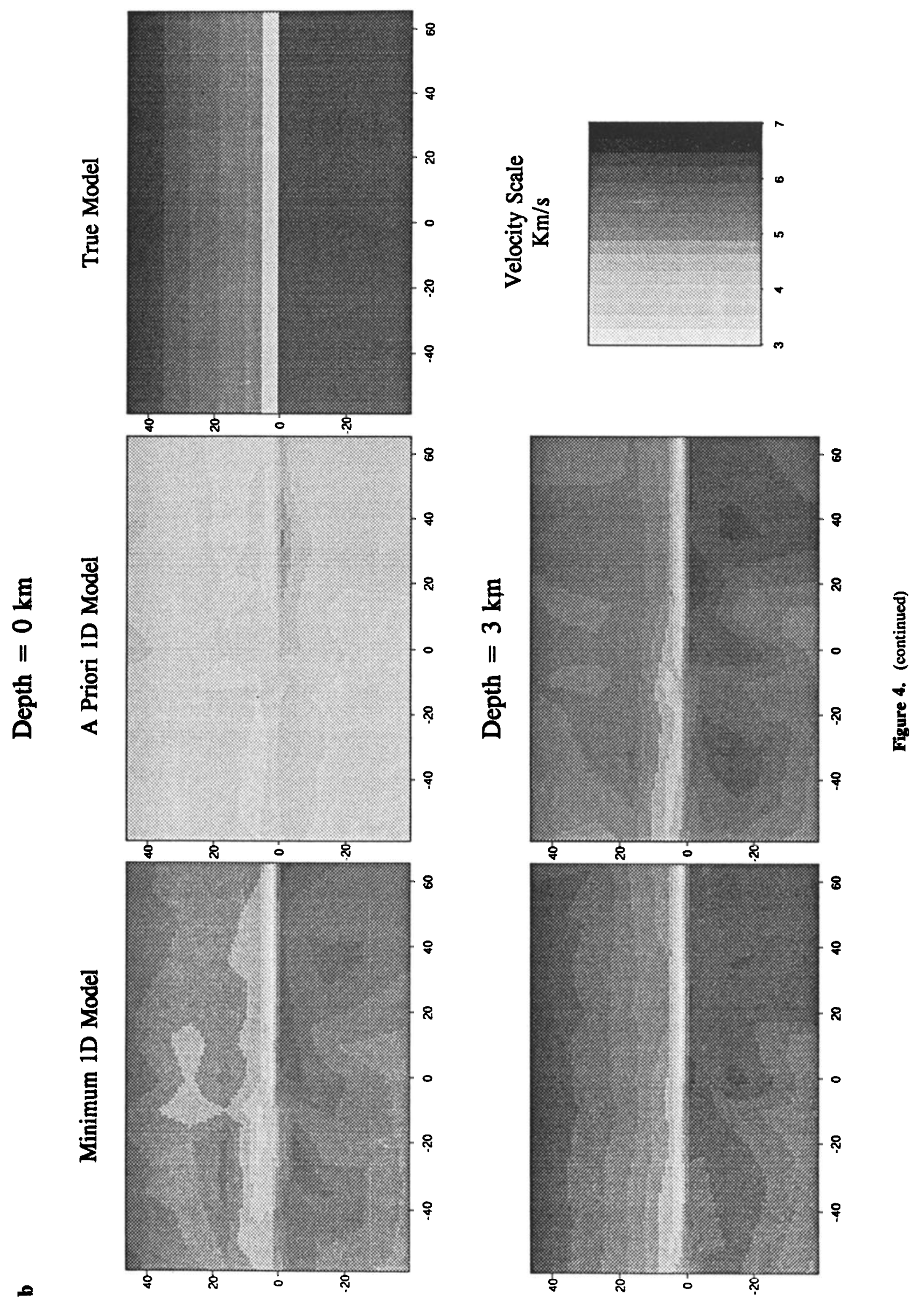




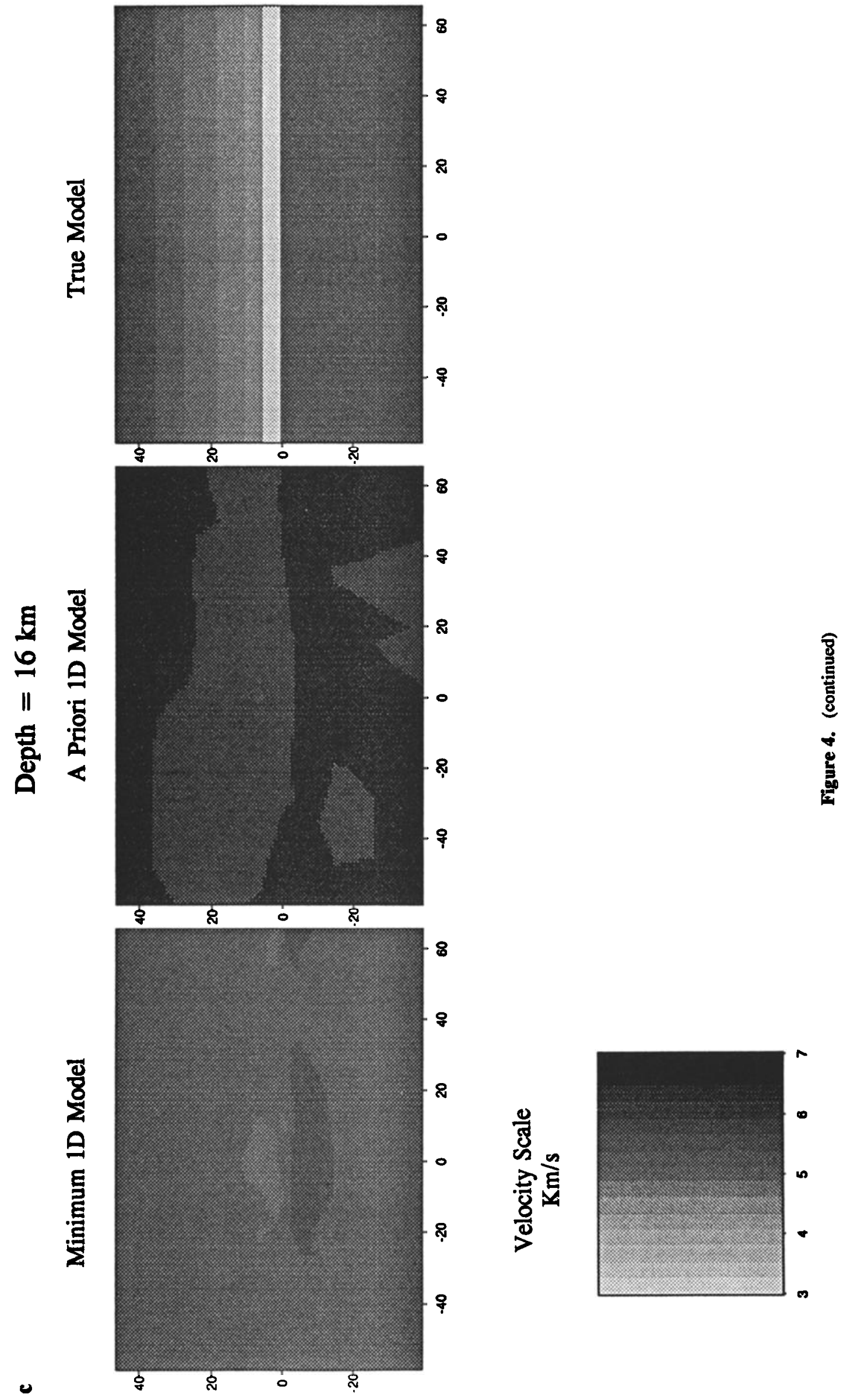




\section{Minimum 1D Model}

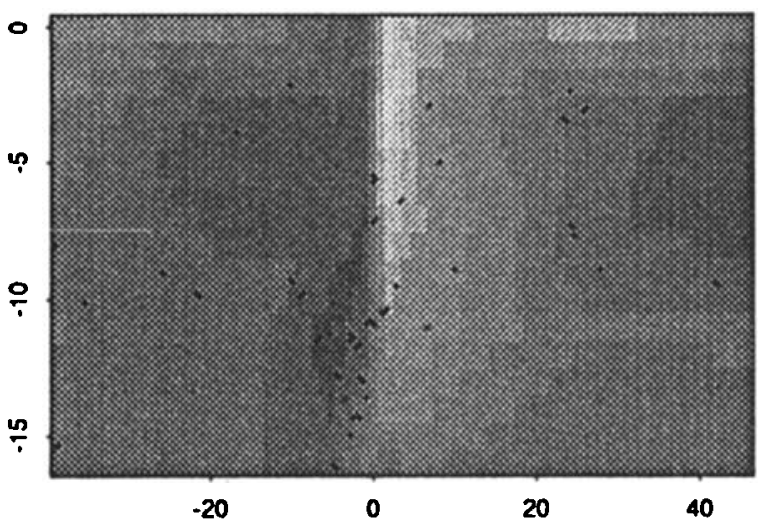

A Priori 10 Model

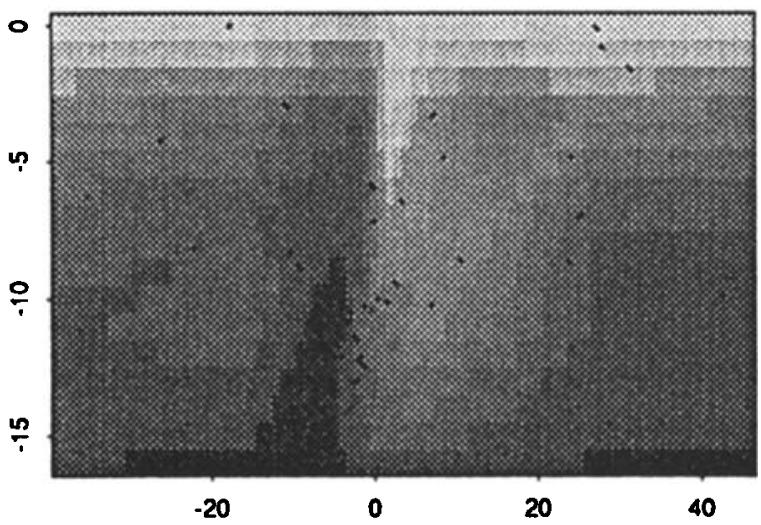

True Model

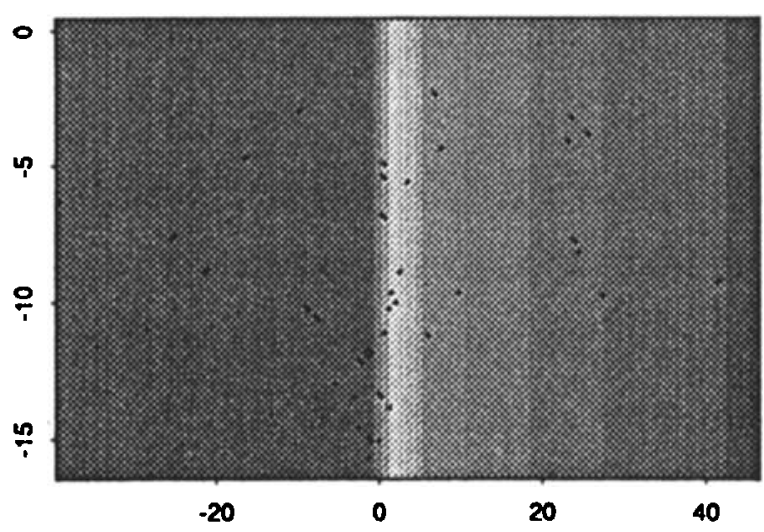

Figure 5. Vertical cross sections perpendicular to San Andreas Fault at $Y=10$ (see Figures 2 and 4 for location) of resulting 3-D velocity field for synthetic Loma Prieta data (see text). Coordinates are parallel ( $Y$ axis) and perpendicular ( $X$ axis) to San Andreas fault (for velocity grid, see Figure 2). Distances are in kilometers. Dots are hypocenter locations. (top) Results based on minimum 1-D model (Figure 3, open circles) as reference model. (middle) Results based on a priori 1-D model (Figure 3, solid squares) as reference model. (bottom) True velocity field. model. Systematic error in the starting model will not only influence the 3-D results but will also distort the resulting error estimates.

The particular method we have used [Thurber, 1981; Eberhart-Phillips, 1990] to solve the inverse problem simultaneously updates the hypocenters, ray paths, and travel times at each iteration step and terminates the iteration only after perturbations became statistically insignificant. Perhaps another inversion strategy would succeed in finding a better minimum when the a priori 1-D model is the starting point, but this must be demonstrated. Our results thus illustrate the potential ambiguity in this specific inverse problem With real data, however, we are forced to rely upon other tests, including sensitivity tests Lees and Shalev [1992], "checkerboard" tests Spakman [1991], error and resolution estimates Koch [1993], and smoothing test Sambridge [1990] to select the most probable results. Cross validation is also highly recommended, particularly as a means to select the proper damping to regularize the solution [Segall and $D u, 1993$ ].

One worrisome problem with both our derived models is the appearance of long-wavelength artifacts in the lower half of each model that are just of the type that might be mistaken for structure (Figures 4 and 5). Each model contains a highvelocity body immediately to the Southwest of the fault zone (below the zone in Figure 4 and to its left in Figure 5) that approximately corresponds to the distribution of the deepest hypocenters (those that correspond to the main dipping aftershock zone of the Loma Prieta earthquake [Dietz and Ellsworth, 1990]). Note that the hypocenters (dots in Figure 5) are slightly out of place due to the velocity pull-up effect of the high velocity artifact. Because this feature correlates well between our two estimates, there would be a strong temptation to interpret it as a true part of the 3-D velocity field.

It is also somewhat troubling that a similar high velocity body appears in the tomographic models of the Loma Prieta region [Eberhart-Phillips et al., 1990; Lees, 1990]. One common link between these studies is their use of the routinely determined USGS hypocenters as the initial locations. These hypocenters were computed using the minimum 1-D model of Dietz and Ellsworth [1990], which make them our ideal recommendation for the initial reference model. We cannot say, without further investigation, if the appearance of a similar high-velocity body in our synthetic example casts doubt on the reality of this body, but caution is clearly suggested.

Using a similar data set from Loma Prieta region, Lees and Shalev [1992] investigated the stability of 3-D tomographic results for the actual Loma Prieta data set. They found that various initial velocity models, different parameterization, and either linear or nonlinear inversion procedures all produced similar 3-D velocity fields. In particular, Lees and Shalev [1992, p. 1838] conclude, that " at least for this particular data set, the initial starting models used routinely for earthquake location [i.e., the Dietz-Ellsworth minimum 1-D model] are close enough to the final three-dimensional non linear models such that first-order perturbation theory is sufficient for deriving the primary signal in the data and determining the geometry of three-dimensional slowness field".

In their study, Lees and Shalev [1992] employed the stepwise inversion strategy in which adjustments to the velocity model are determined without perturbing the hypocenters. The hypocenters may be updated in the revised 
model when the procedure is iterated. As they always linearize around the same hypocenter locations and station corrections from the Dietz-Ellsworth minimum 1-D model in the initial velocity step and regularize the solution with horizontal smoothing, it is not surprising that their first velocity step moves them toward a common model, regardless of the other assumptions being tested. Correlation between models derived with different starting models may not, however, be a good measure of reliability, as artifacts in our synthetic model results (Figures 4 and 5 ) correlate well between models.

We also note an apparent difference between our result of a strong dependence on the initial model and those of Pavlis and Booker [1983], who found only a moderate influence of the starting model on recovery of $1-D$ velocity models. Their results agree well with our experience in determining minimum 1-D models in many areas around the world [e.g., Kissling et al., 1984; Kissling, 1988; Kradolfer, 1989; Hauksson and Jones, 1989; Dietz and Ellsworth, 1990; Eberhart-Phillips, 1990; Scott, 1992; Castillo and Ellsworth, 1993]. The stronger dependence of the tomographic images presented here on the initial 1-D model suggests that the local earthquake tomography problem in three dimensions is less well behaved than its 1-D counterpart. This should not be surprising, as in going from one to three dimensions, we replace an infinitely long horizontal averaging kernel with one of finite length. Use of the least squares solution to the 1-D tomography problem with earthquake hypocenters stabilised in that model as the point of departure for 3-D modeling can therefore do nothing but improve the chances for successful 3-D modeling.

\section{Appendix: "Recipe" to Calulate a Minimum 1-D Model}

The following guidelines for the calculation of a minimum 1-D model have been developed through the application of equation (3) in many areas of both simple and complex crustal structure around the world [Reasenberg and Ellsworth, 1982; Kissling and Lahr, 1991; Maurer, 1993]. These guidelines do not guarantee convergence to an optimal solution. Rather, specific characteristics of the data set, and of the velocity structure may demand modifications of the procedure. The results also depend on the effectiveness of the data selection process [Kissling, 1988].

Most of our modelling has been done with the program VELEST [Ellsworth, 1977; Roecker, 1981; Kradolfer, 1989]. The programs of Crosson [1976] and Pavlis and Booker [1980] have also enjoyed considerable success for this purpose [Steppe and Crosson, 1978]. Scott [1992] has recently conducted a thorough investigation of the problem.

\section{Step 1. Establishing the a Priori 1-D Model(s)}

Obtain all available a priori (prior to the one or threedimensional inversion) information regarding the stratification of the area under study (velocities, layer thicknesses, etc.). In general, use refraction seismic models, simplified where necessary to constant velocity layers. If no controlled-source seismology models are available, use phase correlations and cross over distances [e.g., Deichmann, 1987] from well-recorded earthquakes and/or infer the layered structure from geologic information. Define the media by several layers of increasing velocity with depth. Thicknesses of the layers in the upper crust should be about $2 \mathrm{~km}$ and in the lower crust about 4 to $5 \mathrm{~km}$. Estimate layer velocities according to a priori information or a general crustal model. In case of incomplete or inconsistent information or, if the area under consideration confines two or more distinctly different tectonic provinces, establish several 1-D models. Choose a reference station with a continuous or nearly continuous record of events. It must be a reliable station, preferably located toward the center of the network and should not show extreme site effects. The model(s) and the reference station are called the a priori 1-D model(s). If several significantly different a priori 1-D models are established the following steps 2 through 5 are repeated for each 1-D model seperately.

\section{Step 2. Establishing the Geometry and the Velocity Intervals of Potential 1-D Model(s)}

Select about 500 of the best events in the data (i.e., those with the most high-quality $P$ arrivals) that cover the entire area under consideration. Relocate them with routine VELEST using a damping coefficient of 0.01 for the hypocentral parameters and the station delays and 0.1 for the velocity parameters. Invert for hypocenters every iteration and for station delays and velocity parameters every second iteration. Repeat this procedure several times with new (updated) velocities in the reference 1-D model, with perhaps the new station delays, and with new hypocenter locations. Repeat the procedure also for reduced number of layers where possible by combining adjacent layers with similar velocities. Unless clearly indicated by the data, in most cases it is preferable to avoid low velocity layers, as they normally introduce instabilities.

Our experience suggests that shot or blast data should not be included in the 1-D model inversion. Rather, such data should be used to set the near-surface velocities, and to test the performance of the resulting minimum 1-D model when used for locating hypocenters. This countrintuitive suggestion may be understood by considering that ray paths with both endpoints near the surface sample, on average, a much more heterogeneous part of the Earth than do ray paths from events in the seismogenic crust.

The goal of this trial and error approach is to establish reasonable geometry of the crustal model and corresponding intervals for the velocity parameters and station delays. In addition, this approach provides valuable knowledge about the quality of the data. Procede to the next step when (1 the earthquake locations, station delays, and velocity values do not vary significantly in subsequent runs; ( 2 the total RMS value of all events shows a significant reduction with respect to the first routine earthquake locations; and (3 the calculated $1-D$ velocity model and the set of station corrections make some geological sense (e.g., stations with negative travel time residuals should lie in local high-velocity areas with respect to the reference station, etc.) and do not violate a priori information. If all these requirements are satisfied, the result may be called the "updated a priori 1-D model with corresponding station residuals".

\section{Step 3. Relocation and Final Selection of Events}

Relocate all events using the updated a priori 1-D model with station residuals with a routine location procedure (HYPO71 [Lee and Lahr, 1975], HYPOINVERSE [Klein, 1978], HYPOELLIPSE [Lahr , 1980]) or with VELEST in the singleevent mode (fixing the station and velocity parameters). 
Reselect the best (consider gap, number of observations, distance to next station) 500 or so events that should be well distributed over the volume under investigation. If more than one such subset of about 500 events can be extracted, proceed for each subset separately with step 4 but try to obtain similar results.

\section{Step 4. Calculation of Minimum 1-D Model for One Subset}

In general terms, repeat step 2 with the updated a priori 1-D model and station residuals and with a damping of 0.01 for the hypocentral, 0.1 for the station, and 1.0 for the velocity parameters. The goal of this step is to calculate the 1-D model (velocity parameters and station residuals) that minimizes the total estimated location errors for a fixed geometry. Test the stability of the result by systematically and randomly shifting hypocenters and by underdamping the velocity parameters. If you are pleased with the performance of the solution, fix the updated velocity parameters by overdamping and calculate the station residuals. The resulting velocity model with corresponding station residuals is called "minimum 1-D model".

\section{Step 5. Calculation of Minimum 1-D Model for Several Subsets}

If several subsets of 500 events were extracted, test the dependence of your minimum 1-D model on specific data. Find the 1-D model and station residuals that will best fit the results from all subsets, mix data from different subsets, and repeat step 4 . If the results are unsatisfactory, evaluate the best 1-D model by the procedure described in step 6 .

\section{Step 6. Evaluation of Different Minimum 1-D Models for Same Area}

If several significantly different a priori 1-D models were established and steps 2 through 5 were successfully completed for each of them, you may base your choice of one minimum 1$D$ model on the result of the following performance test: Select all travel time data from quarry blasts or shots (i.e., from sources of known location) and relocate these events for the different minimum 1-D models without fixing the depth during the location process. If the near-surface velocities for several station locations are known, compare the station residuals with the differences between the average layer velocity and the local velocities. Finally, select the minimum 1-D model that best resembles the a priori information.

Acknowledgments. We thank A. Green, M. Baumann, and J. Ansorge (ETH Zurich) for their criticism and suggestions that improved the manuscript. For their constructive criticism and thorough reviews we also thank C. Thurber, G. Pavlis, H. Benz, and W. Lutter. Last, but certainly not least, we are indebted to A. Michilini and to J. Scott, who each independently performed blind 3-D model studies of the synthetic data using essentially the same modeling strategy we have advocated here. Happily, they both achieved results as satisfactory as those presented here. Contr. No. 711 Institute of Geophysics, ETH-Zürich, Switzerland.

\section{References}

Aki, K., and W.H.K Lee, Determination of three-dimensional velocity anomalies under a seismic array using first $P$ arrival times from local earthquakes, 1, A homogeneous initial model, J. Geophys. Res., 81, 4381-4399, 1976.

Allen, R.V., Automatic phase pickers; their present use and future prospects, Bull. Seismol. Soc. Am., 72, S225-S242, 1982.

Castillo, D. A., and W.L. Ellsworth, Seismotectonics of the San Andreas fault system between Point Arena and Cape Mendocino in northem California: Implications for the development and evolution of a young transform, J. Geophys. Res., 98, 6543-6560, 1993.

Crosson, R.S., Crustal structure modelling of earthquake data, 1, Simultaneous least squares estimation of hypocenter and velocity parameters, J. Geophys. Res., 81, 3036-3046, 1976.

Deichmann, N., Focal depths of earthquakes in northem Switzerland, Ann. Geophys., 4, 395-402, 1987.

Dietz, L. D., and W. L. Ellsworth, The October, 17, 1989 Loma Prieta, California, earthquake and its aftershocks: Geometry of the sequence from high-resolution locations, Geophys. Res. Lett., 17, 1417-1420, 1990.

Dziewonski, A.M., Mapping the lower mantle: Determination of lateral heterogeneity in $P$ velocity up to degree and order $6, J$. Geophys. Res., 89, 5929-5952, 1984.

Eberhart-Phillips, D., Three-dimensional $P$ and $S$ velocity structure in the Coalinga region, Califomia, J. Geophys. Res., 95, 15,343-15,363, 1990.

Eberhart-Phillips, D., and A.J. Michael, Three-dimensional velocity structure, seismicity, and fault structure in the Parkfield region, central Califomia, J. Geophys. Res., 98, 737-758, 1993.

Eberhart-Phillips, D., V.F. Labson, W.D. Stanley, A.J. Michael, and B. D. Rodriguez, Preliminary velocity and restivity models of the Loma Prieta earthquake region, Geophys. Res. Lett., 17, 1235-1238, 1990.

Ellsworth, W.L., Three-dimensional structure of the crust and mantle beneath the island of Hawaii, Ph.D. thesis, Mass. Inst. of Technol., Cambridge, 1977.

Feng, R., and T.V. McEvilly, Interpretation of seismic reflection profiling data for the structure of the San Andreas fault zone, Bull. Seismol. Soc. Am., 73, 1701-1720, 1983.

Foxall, W., A. Michilini, and T.V. McEvilly, Earthquake travel time tomography of the Southem Santa Cruz Mountains: Control of fault rupture by lithological heterogeneity of the San Andreas fault zone, J. Geophys. Res., 98, 17,691-17,710, 1993.

Hauksson, E., and L.M. Jones, The 1987 Whittier Narrows earthquake sequence in Los Angeles, southem California, J. Geophys. Res., 94, 9567-9589, 1989.

Healy, J.H., and L.G. Peake, Seismic velocity structure along the San Andreas fault near Bear Valley, California, Bull. Seismol. Soc. Am., 65, 1177-1197, 1975.

Kissling, E., Geotomography with local earthquake data, Rev. Geophys., 26, 659-698, 1988.

Kissling, E., and J. C. Lahr, Tomographic image of the Pacific slab under southem Alaska, Eclogae Geol. Helv., 84, 297-315, 1991.

Kissling, E., W.L. Ellsworth, and R. Cockerham, Three-dimensional structure of the Long Valley Caldera, California, region by geotomography, U.S. Geol. Surv. Open File Rep., 84-939, 188-220, 1984.

Klein, R.W., Hypocenter location program HYPOINVERSE, I, Users guide to versions 1,2,3, and 4, U.S. Geol. Surv. Open File Rep., 78694, 1978.

Koch, M., Simultaneous inversion for 3-D crustal structure and hypocentres including direct, refracted and reflected phases, I, Development, validation and optimal regularization of the method, Geophys. J. Int., 112, 385-412, 1993.

Kradolfer, U., Seismische Tomographie in der Schweiz mittels lokaler Erdbeben, Ph.D. thesis, 109 p., Eidg. Techn. Hochschule (ETH) Zürich, 1989.

Lahr, J.C., HYPOELLIPSE/MULTICS: A computer program for determining local earthquake hypocentral parameters, magnitude, and first motion pattern, U.S. Geol. Surv. Open File Rep., 80-59, 1980.

Lee, W.H.K., and J. C. Lahr, HYPO71: A computer program for determining hypocenter, magnitude, and first motion pattem of local earthquakes, U.S. Geol. Survey Open File Rep., 75-311, 1975. 
Lees, J. M., Tomographic $P$ wave velocity images of the Loma Prieta earthquake asperity, Geophys. Res. Lett., 17, 1433-1436, 1990.

Lees, J. M., and E. Shalev, On the stability of P-wave tomography at Loma Prieta: A comparison of parameterizations, linear and nonlinear inversions, Bull. Seismol. Soc. Am., 83, 1821-1839, 1992.

Maurer, H.R., Seismotectonics and upper crustal structure in the westem Swiss Alps, Ph.D. thesis, 133 p., Eidg. Techn. Hochschule (ETH) Zürich, 1993.

Michael, A. J., Effects of three-dimensional velocity structure on the seismicity of the 1984 Morgan Hill, California, aftershock sequence, Bull. Seismol. Soc. Am., 78, 1199-1221, 1988.

Mooney, W.D., and R. H. Colbum, A seismic refraction profile across the San Andreas, Sargent, and Calaveras faults, west-central Califomia, Bull. Seismol. Soc. Am., 75, 175-191, 1985.

Nolet, G., Simultaneous inversion of seismic data, Geophys. J. R. Astron. Soc., 55, 679-691, 1978.

Pavlis, G.L., and J. R. Booker, The mixed discrete-continuous inverse problem: Application to the simultaneous determination of earthquake hypocenters and velocity structure, J. Geophys. Res., 85, 4801-4810, 1980.

Pavlis, G.L., and J. R. Booker, A study of the importance on nonlinearity in the inversion of earthquake arrival time data for velocity structure, J. Geophys. Res., 88, 5047-5055, 1983.

Reasenberg, P., and W.L. Ellsworth, Aftershocks of the Coyote Lake, Califomia, earthquake of August 6, 1979: A detailed study, $J$. Geophys. Res., 87, 10,637-10,655, 1982.

Roecker, S. W., Seismicity and tectonics of the Pamir-Hindu Kush region of central Asia, Ph.D. thesis, Mass. Inst. of Technol., Cambridge, 1981.

Sambridge, M. S., Non-linear arrival time inversion: constraining velocity anomalies by seeking smooth models in 3-D, Geophys. $J$. Int., 102, 653-677, 1990.

Scott, J.S., Microearthquake studies in the Anza seismic gap, Ph.D. thesis, 277 p., Univ. of Calif., San Diego, Scripps Inst. of Oceanogr., La Jolla, 1992.

Segall, P., and Y. Du, How similar were the 1934 and 1966 Parkfield earthquakes?, J. Geophys. Res., 98, 4527-4539, 1993.

Spakman, W., Delay-time tomography of the upper mantle below Europe, the Mediterranean, and Asia Minor, Geophys. J. Int., 107, 309-332, 1991.

Spakman, W., and G. Nolet, Imaging algorithms, accuracy and resolution in delay time tomography, in Mathematical Geophysics, edited by N.J. Vlaar, G. Nolet, M.J.R. Wortel, and S.A.P.L. Cloeting, eds.,D. Reidel Publ. Co.,155-187, 1988.
Spencer, C., and D. Gubbins, Travel time inversion for simultaneous earthquake location and velocity structure determination in laterally varying media, Geophys. J. R. Astron. Soc., 63, 95-116, 1980.

Steppe, J. A., and R. S. Crosson, P-velocity models of the southem Diablo Range, California, form inversion of earthquake and explosion arrival times, Bull. Seismol. Soc. Am., 68, 357-367, 1978.

Thurber, C.H.: Earth structure and earthquake locations in the Coyote Lake area, central California, Ph.D. thesis, Mass. Inst. of Technol., Cambridge, 1981.

Thurber, C. H., Nonlinear earthquake location: Theory and examples, Bull. Seismol. Soc. Am., 75, 779-790, 1985.

Thurber, C.H., Hypocenter-velocity structure coupling in local earthquake tomography, Phys. Earth Planet. Inter., 75, 55-62, 1992.

Thurber, C.H., and W.L. Ellsworth, Rapid solution of raytracing problems in heterogeneous media, Bull. Seismol. Soc. Am., 70, 1137$1148,1980$.

Um, J., and C. H. Thurber, A fast algorithm for two-point seismic ray tracing, Bull. Seismol. Soc. Am., 61, 729-746, 1987.

vander Hilst, R.D., and W. Spakman, Importance of the reference model in linearized tomography and images of subduction below the Caribbean plate, Geophys. Res. Lett, 16, 1093-1096, 1989.

vander Hilst, R.D., R. Engdahl, W. Spakman and G. Nolet, Tomographic imaging of subducted lithosphere below northwest Pacific island arcs, Nature, 353, 37-43, 1991.

Vidale, J.E., Finite-difference calculation of travel times in three dimensions, Geophysics, 55, 521-526, 1990.

Walter, A.W., and W.D. Mooney, Crustal structure of the Diablo and Gabilan Ranges, central California: A reinterpretation of existing data, Bull. Seismol. Soc. Am., 72, 1567-1590, 1982.

D. Eberhart-Phillips, Institute of Geological and Nuclear Sciences, 32 Salamanca Road, Wellington, New Zealand. (e-mail: Internet donna@lottol.gns.cri.nz)

W.L. Ellsworth, U.S. Geological Survey, 345 Middlefield Rd, MS 977, Menlo Park, CA 94025, (e-mail: Internet ellwrth@andreas. wr.usgs.gov)

E. Kissling and U. Kradolfer, Institute of Geophysics, ETHHoenggerberg, CH-8093 Zurich, Switzerland. (e-mail: Intemet kiss@tomo.ifg.ethz.ch; kradi@seismo.ifg.ethz.ch)

(Received September 17, 1992; revised October 26, 1993;

accepted November 4, 1993.) 